\title{
THE ZMOA-1990 NUTATION SERIES
}

\author{
T. A. HERRDNG \\ Massachusetts Institute of Technology, 54-618 \\ 77 Massachusetts Avenue, \\ Cambridge, MA. 02319.
}

\begin{abstract}
We present a new nutation series for the Earth (ZMOA-1990) based on (1) the rigid Earth nutation series developed by Zhu and Groten [1989], (2) the normalized response for an elastic, elliptical Earth with fluid-outer and solid-inner cores developed by Mathews et al. [1990], and (3) corrections for the effects of ocean tides and anelasticity, computed to be consistent with the Mathews at al. [1990] normalized response function. In deriving this series, only two parameters of the geophysical model for the Earth have been modified from their values computed with PREM: the dynamic ellipticities of the whole Earth, $e$, and of the fluid outer core, ef. The adopted values for these parameters, determined from the analysis of very long baseline interferometry (VLBI) data, are $e=0.00328915$ which is about $1 \%$ higher than the value obtained from PREM and $6 \times 10^{-5}$ times larger than the IAU adopted value, and $e_{f}=0.002665$ which is $4.6 \%$ higher than the PREM value. The above values were obtained from an adjustment of -0.3 "/cent to the IAU-1976 luni-solar precession constant for $e$, and from the amplitude of the retrograde annual nutation for $e_{f}$. The ZMOA-1990 nutation series agrees with estimates of the in-phase and the out-of-phase nutation amplitudes obtained from VLBI data to within 0.5 mas for the terms with 18.6 year period, and to better than 0.1 mas for terms at all other periods except for the out-of-phase terms with annual period (differences 0.39 mas, retrograde, and 0.13 mas, prograde), and for the in-phase term with prograde 13.66 day period (difference -0.25 mas).
\end{abstract}

\section{Introduction}

It has been apparent for about 5 years now that the IAU-1980 nutation series [Seidelmann, 1982] is inadequate for defining the motion of the Earth in inertial space with sufficient precision for the analysis of modern spaced-based geodetic data [see e.g., Herring et al., 1986]. There are a number of deficiencies in the IAU-1980 series arising both from the assumptions made in the geophysical models used in its derivation and from the nutation series of the rigid body that is convolved with the normalized response function of the Earth. We present here a new nutation series which overcomes, to a large degree, the deficiencies in the IAU-1980 series. This new series is based on the rigid Earth nutation series of Zhu and Groten [1989] with a slight modification discussed below, and the normalized response for an elastic, elliptical Earth with fluidouter and solid-inner cores developed by Mathews et al. [1990a and $b$ ]. Effects of mantle anelasticity and ocean tides are explicitly included in this new series with the specific corrections used based on a recomputation of the models used by Wahr and Sasao [1981] for ocean tides and Wahr and Bergen [1986] for anelasticity. This new series, which we refer to as ZMOA-1990 (Zhu, Mathews, Qceans and Anelasticity), is discussed fully in Herring et al. [1990], and we restrict our discussions here to specific aspects of it. We also give the new series and two variants in their entirety.

The aim of the Mathews et al. [1990a and b] and the Herring et al. [1990] sequence of papers was to assess the geophysical signals which could be studied using nutations and to assess the agreement between an almost purely geophysical model for the nutations and the "observed" series obtained from the analysis of very long baseline interferometry (VLBI) data. Only two parameters of the Earth derived from the Preliminary Reference Earth Model (PREM) of Dziewonski and Anderson [1981] are modified in computing the normalized response function of the Earth for the ZMOA-1990 series: namely, the dynamical ellipticities of the whole Earth, $e$, and of the fluid core, $e_{f}$. It has been known for sometime that values of $e$ computed 
assuming that the Earth is in hydrostatic equilibrium and using the radially symmetric density distribution from seismic-based Earth models are not consistent with the value required to explain the luni-solar precession constant. The difference is usually about $1 \%$. We have further modified the standard astronomical value of $e$ by a fractional change $6 \times 10^{-5}$ to be consistent with a correction of $-0.3 \%$ "cent to the standard value of the precession constant that is now being obtained from the analysis of VLBI data $(-0.32 \pm 0.13$ "/cent) [Herring et al., 1990] and lunar laser ranging data $(-0.27 \pm 0.04 \mathrm{M} / \mathrm{cent})$ [Williams et al., 1990]. The need for a modification of the value of the dynamic ellipticity of the fluid core computed assuming that the Earth is in hydrostatic equilibrium is also well established from nutation studies [Gwinn et al., 1986]; from seismology [Hager et al., 1985; Morelli and Dziewonski, 1987], and from gravimetry [Neuberg et al., 1987]. The 4.6\% increase in the value of ef used in the ZMOA-1990 series is consistent with values obtained in previous analyses. The models for the effects of ocean tides and mantle anelasticity have also been re-computed to be consistent with ef and with the 0.01 mas truncation level used in the Zhu and Groten rigid Earth series and ZMOA-1990. The comparison of the VLBI derived series and the geophysical series did influence the choice of anelasticity models in that the QMU model of Sailor and Dziewonski [1978] is favored over the $\beta$ model of Sipkin and Jordan [1980] because the former is more consistent with the VLBI derived series. The ZMOA1990 series with ocean tide and anelasticity effects included in the series coefficients is given in Table 1 . In addition to containing more terms than the IAU-1980 one, this series also contains out-of-phase terms which are necessitated by the incorporation of anelasticity and ocean tide contributions.

TABLE 1. The ZMOA-1990 nutation series.

\begin{tabular}{|c|c|c|c|c|c|c|c|c|c|c|c|}
\hline \multicolumn{5}{|c|}{$\begin{array}{c}\text { Fundamental } \\
\text { arguments }\end{array}$} & \multirow{2}{*}{$\begin{array}{c}\text { Period } \\
\text { (solar days) }\end{array}$} & \multirow{2}{*}{$\begin{array}{c}\Delta \psi_{i n} \\
\text { (mas) }\end{array}$} & \multirow{2}{*}{$\begin{array}{c}\Delta \dot{\psi}_{i n} \\
\text { (mas/cy) }\end{array}$} & \multirow{2}{*}{$\begin{array}{c}\Delta \varepsilon_{i n} \\
\text { (mas) }\end{array}$} & \multirow{2}{*}{$\begin{array}{c}\Delta \dot{\varepsilon}_{i n} \\
\text { (mas/cy) }\end{array}$} & \multirow{2}{*}{$\begin{array}{l}\Delta \psi_{\text {out }} \\
\text { (mas) }\end{array}$} & \multirow{2}{*}{$\begin{array}{l}\Delta \varepsilon_{\text {out }} \\
\text { (mas) }\end{array}$} \\
\hline$I$ & $r$ & $F$ & $D$ & $\boldsymbol{\Omega}$ & & & & & & & \\
\hline $\mathbf{0}$ & 0 & 0 & 0 & 1 & -6798.383 & -17206.34 & -17.43 & 9205.11 & 0.90 & 1.90 & 0.98 \\
\hline 0 & 0 & 2 & -2 & 2 & 182.621 & -1317.18 & -0.16 & 573.06 & -0.31 & -1.41 & -0.46 \\
\hline 0 & 0 & 2 & 0 & 2 & 13.661 & -227.56 & -0.02 & 97.79 & -0.05 & -0.02 & 0.01 \\
\hline 0 & 0 & 0 & 0 & 2 & -3399.192 & 207.50 & 0.02 & -89.77 & 0.05 & -0.05 & -0.02 \\
\hline 0 & 1 & 0 & 0 & 0 & 365.260 & 147.60 & -0.36 & 7.30 & 0.02 & -0.12 & 0.09 \\
\hline 1 & 0 & 0 & 0 & 0 & 27.555 & 71.11 & 0.01 & -0.67 & 0.00 & -0.03 & 0.03 \\
\hline 0 & 1 & 2 & -2 & 2 & 121.749 & -51.69 & 0.12 & 22.44 & 0.07 & -0.06 & -0.02 \\
\hline 0 & 0 & 2 & 0 & 1 & 13.633 & -38.71 & -0.04 & 20.06 & 0.00 & -0.01 & 0.00 \\
\hline 1 & 0 & 2 & 0 & 2 & 9.133 & -30.13 & 0.00 & 12.89 & -0.01 & 0.03 & 0.01 \\
\hline 0 & -1 & 2 & -2 & 2 & 365.225 & 21.61 & -0.05 & -9.60 & 0.03 & 0.02 & 0.01 \\
\hline 1 & 0 & 0 & -2 & 0 & -31.812 & -15.70 & 0.00 & -0.13 & 0.00 & -0.01 & -0.01 \\
\hline 0 & 0 & 2 & -2 & 1 & 177.844 & 12.91 & 0.01 & -6.98 & 0.00 & 0.02 & 0.00 \\
\hline-1 & 0 & 2 & 0 & 2 & 27.093 & 12.35 & 0.00 & -5.33 & 0.00 & 0.01 & 0.00 \\
\hline 1 & 0 & 0 & 0 & 1 & 27.667 & 6.32 & 0.01 & -3.32 & 0.00 & 0.00 & 0.00 \\
\hline 0 & 0 & 0 & 2 & 0 & 14.765 & 6.36 & 0.00 & 0.12 & 0.00 & 0.00 & 0.00 \\
\hline 1 & 0 & 2 & 2 & 2 & 9.557 & -5.96 & 0.00 & 2.55 & 0.00 & 0.00 & 0.00 \\
\hline-1 & 0 & 0 & 0 & 1 & -27.443 & -5.81 & -0.01 & 3.15 & 0.00 & 0.00 & 0.00 \\
\hline$i$ & 0 & 2 & 0 & i & 9.121 & -5.15 & 0.00 & 2.64 & 0.00 & 0.00 & 0.00 \\
\hline 2 & 0 & 0 & -2 & 0 & 205.892 & 4.79 & 0.00 & 0.05 & 0.00 & 0.00 & 0.00 \\
\hline-2 & 0 & 2 & 0 & 1 & 1305.479 & 4.60 & 0.00 & -2.43 & 0.00 & 0.00 & 0.00 \\
\hline 0 & 0 & 2 & 2 & 2 & 7.096 & -3.84 & 0.00 & 1.64 & 0.00 & 0.00 & 0.00 \\
\hline 2 & 0 & 2 & 0 & 2 & 6.859 & -3.09 & 0.00 & 1.32 & 0.00 & 0.00 & 0.00 \\
\hline 2 & 0 & 0 & 0 & 0 & 13.777 & 2.93 & 0.00 & -0.06 & 0.00 & 0.00 & 0.00 \\
\hline$i$ & 0 & 2 & -2 & 2 & 23.942 & 2.86 & 0.00 & -124 & 0.00 & 0.00 & 0.00 \\
\hline 0 & 0 & 2 & 0 & 0 & 13.606 & 259 & 0.00 & -0.05 & 0.00 & 0.00 & 0.00 \\
\hline 0 & 0 & 2 & -2 & 0 & 173.310 & -2.19 & 0.00 & -0.01 & 0.00 & 0.00 & 0.00 \\
\hline-1 & 0 & 2 & 0 & 1 & 26.985 & 2.05 & 0.00 & -1.07 & 0.00 & 0.00 & 0.00 \\
\hline 0 & 2 & 0 & 0 & 0 & 182.630 & 1.68 & -0.01 & 0.02 & 0.00 & 0.00 & 0.00 \\
\hline 0 & 2 & 2 & -2 & 2 & 91313 & -1.58 & 0.01 & 0.69 & 0.00 & 0.00 & 0.00 \\
\hline-1 & 0 & 0 & 2 & 1 & 31.961 & 1.52 & 0.00 & -0.80 & 0.00 & 0.00 & 0.00 \\
\hline 0 & 1 & 0 & 0 & $i$ & 385.998 & -1.40 & 0.00 & 0.86 & 0.00 & 0.00 & 0.00 \\
\hline 1 & 0 & 0 & -2 & 1 & -31.664 & -1.29 & 0.00 & 0.70 & 0.00 & 0.00 & 0.00 \\
\hline 0 & -1 & 0 & 0 & 1 & -346.636 & -1.28 & 0.00 & 0.64 & 0.00 & 0.00 & 0.00 \\
\hline 2 & 0 & -2 & 0 & 0 & -1095.175 & 1.10 & 0.00 & 0.01 & 0.00 & 0.00 & 0.00 \\
\hline
\end{tabular}


TABLE 1 Continued. The ZMOA-1990 nutation series.

\begin{tabular}{|c|c|c|c|c|c|c|c|c|c|c|c|}
\hline \multicolumn{5}{|c|}{$\begin{array}{c}\text { Fundamental } \\
\text { arguments }\end{array}$} & \multirow{2}{*}{$\begin{array}{c}\text { Period } \\
\text { (solar days) }\end{array}$} & \multirow{2}{*}{$\begin{array}{l}\Delta \psi_{\text {in }} \\
\text { (mas) }\end{array}$} & \multirow{2}{*}{$\begin{array}{c}\Delta \psi_{i n} \\
(\operatorname{mas} / c y)\end{array}$} & \multirow{2}{*}{$\begin{array}{l}\Delta \varepsilon_{\text {in }} \\
\text { (mas) }\end{array}$} & \multirow{2}{*}{$\begin{array}{c}\Delta \dot{\varepsilon}_{\text {in }} \\
\text { (mas/cy) }\end{array}$} & \multirow{2}{*}{$\begin{array}{l}\Delta \psi_{\text {out }} \\
\text { (mas) }\end{array}$} & \multirow{2}{*}{$\begin{array}{l}\Delta \varepsilon_{\text {out }} \\
\text { (mas) }\end{array}$} \\
\hline$l$ & $r$ & $F$ & $D$ & $\Omega$ & & & & & & & \\
\hline-1 & 0 & 2 & 2 & 1 & 9.543 & -1.02 & 0.00 & 0.52 & 0.00 & 0.00 & 0.00 \\
\hline 1 & 0 & 2 & 2 & 2 & 5.643 & -0.77 & 0.00 & 0.32 & 0.00 & 0.00 & 0.00 \\
\hline 0 & -1 & 2 & 0 & 2 & 14.192 & -0.76 & 0.00 & 0.33 & 0.00 & 0.00 & 0.00 \\
\hline 0 & 0 & 2 & 2 & 1 & 7.088 & -0.66 & 0.00 & 0.34 & 0.00 & 0.00 & 0.00 \\
\hline 1 & 1 & 0 & -2 & 0 & -34.847 & -0.74 & 0.00 & -0.01 & 0.00 & 0.00 & 0.00 \\
\hline 0 & 1 & 2 & 0 & 2 & 13.168 & 0.76 & 0.00 & -0.33 & 0.00 & 0.00 & 0.00 \\
\hline-2 & 0 & 0 & 2 & 1 & -199.840 & -0.58 & 0.00 & 0.31 & 0.00 & 0.00 & 0.00 \\
\hline 0 & 0 & 0 & 2 & 1 & 14.797 & -0.64 & 0.00 & 0.33 & 0.00 & 0.00 & 0.00 \\
\hline 2 & 0 & 2 & -2 & 2 & 12.811 & 0.65 & 0.00 & -0.28 & 0.00 & 0.00 & 0.00 \\
\hline 1 & 0 & 0 & 2 & 0 & 9.614 & 0.66 & 0.00 & -0.02 & 0.00 & 0.00 & 0.00 \\
\hline 1 & 0 & 2 & -2 & 1 & 23.858 & 0.58 & 0.00 & -0.30 & 0.00 & 0.00 & 0.00 \\
\hline 0 & 0 & 0 & -2 & 1 & -14.733 & -0.50 & 0.00 & 0.28 & 0.00 & 0.00 & 0.00 \\
\hline 0 & -1 & 2 & -2 & 1 & 346.604 & -0.48 & 0.00 & 0.28 & 0.00 & 0.00 & 0.00 \\
\hline 2 & 0 & 2 & 0 & 1 & 6.852 & -0.53 & 0.00 & 0.26 & 0.00 & 0.00 & 0.00 \\
\hline 1 & -1 & 0 & 0 & 0 & 29.803 & 0.47 & 0.00 & -0.01 & 0.00 & 0.00 & 0.00 \\
\hline 1 & 0 & 0 & -1 & 0 & 411.784 & -0.46 & 0.00 & -0.07 & 0.00 & 0.00 & 0.00 \\
\hline 0 & 0 & 0 & 1 & 0 & 29.531 & -0.40 & 0.00 & 0.01 & 0.00 & 0.00 & 0.00 \\
\hline 0 & 1 & 0 & -2 & 0 & -15.387 & -0.44 & 0.00 & -0.01 & 0.00 & 0.00 & 0.00 \\
\hline 1 & 0 & -2 & 0 & 0 & -26.878 & 0.41 & 0.00 & 0.01 & 0.00 & 0.00 & 0.00 \\
\hline 2 & 0 & 0 & -2 & 1 & 212.323 & 0.41 & 0.00 & -0.22 & 0.00 & 0.00 & 0.00 \\
\hline 0 & 1 & 2 & -2 & 1 & 119.607 & 0.36 & 0.00 & -0.20 & 0.00 & 0.00 & 0.00 \\
\hline 1 & $i$ & 0 & 0 & 0 & 25.622 & -0.34 & 0.00 & 0.01 & 0.00 & 0.00 & 0.00 \\
\hline$i$ & -1 & 0 & -1 & 0 & -3232.862 & -0.33 & 0.00 & 0.00 & 0.00 & 0.00 & 0.00 \\
\hline-1 & -1 & 2 & 2 & 2 & 9.814 & -0.29 & 0.00 & 0.12 & 0.00 & 0.00 & 0.00 \\
\hline 0 & -1 & 2 & 2 & 2 & 7.236 & -0.26 & 0.00 & 0.11 & 0.00 & 0.00 & 0.00 \\
\hline 1 & -1 & 2 & 0 & 2 & 9367 & 0.29 & 0.00 & 0.12 & 0.00 & 0.00 & 0.00 \\
\hline 3 & 0 & 2 & 0 & 2 & 5.492 & -0.29 & 0.00 & 0.12 & 0.00 & 0.00 & 0.00 \\
\hline-2 & 0 & 2 & 0 & 2 & 1615.748 & -0.31 & 0.00 & 0.14 & 0.00 & 0.00 & 0.00 \\
\hline $\overrightarrow{1}$ & 0 & 2 & 0 & 0 & 9.108 & 0.34 & 0.00 & -0.01 & 0.00 & 0.00 & 0.00 \\
\hline-1 & 0 & 2 & 4 & 2 & 5.802 & -0.15 & 0.00 & 0.06 & 0.00 & 0.00 & 0.00 \\
\hline 1 & 0 & 0 & 0 & 2 & 27.780 & -0.20 & 0.00 & 0.08 & 0.00 & 0.00 & 0.00 \\
\hline-1 & 0 & 2 & -2 & 1 & -32.606 & -0.20 & 0.00 & 0.11 & 0.00 & 0.00 & 0.00 \\
\hline 0 & -2 & 2 & -2 & 1 & 6786.317 & -0.15 & 0.00 & 0.08 & 0.00 & 0.00 & 0.00 \\
\hline-2 & 0 & 0 & 0 & 1 & -13.749 & -0.23 & 0.00 & 0.13 & 0.00 & 0.00 & 0.00 \\
\hline 2 & 0 & 0 & 0 & 1 & 13.805 & 0.21 & 0.00 & -0.11 & 0.00 & 0.00 & 0.00 \\
\hline 3 & 0 & 0 & 0 & 0 & 9.185 & 0.16 & 0.00 & -0.01 & 0.00 & 0.00 & 0.00 \\
\hline 1 & 1 & 2 & 0 & 2 & 8.910 & 0.24 & 0.00 & -0.10 & 0.00 & 0.00 & 0.00 \\
\hline 0 & 0 & 2 & 1 & 2 & 9.340 & 0.16 & 0.00 & -0.07 & 0.00 & 0.00 & 0.00 \\
\hline 1 & 0 & 0 & 2 & $i$ & 9.627 & -0.10 & 0.00 & 0.05 & 0.00 & 0.00 & 0.00 \\
\hline 1 & 0 & 2 & 2 & 1 & 5.638 & -0.13 & 0.00 & 0.07 & 0.00 & 0.00 & 0.00 \\
\hline 1 & 1 & 0 & -2 & $i$ & -34.669 & -0.06 & 0.00 & 0.03 & 0.00 & 0.00 & 0.00 \\
\hline 0 & 1 & 0 & 2 & 0 & 14.192 & -0.06 & 0.00 & 0.00 & 0.00 & 0.00 & 0.00 \\
\hline 0 & 1 & 2 & -2 & 0 & 117.539 & -0.06 & 0.00 & 0.00 & 0.00 & 0.00 & 0.00 \\
\hline 0 & 1 & -2 & 2 & 0 & -329.791 & -0.09 & 0.00 & 0.00 & 0.00 & 0.00 & 0.00 \\
\hline 1 & 0 & -2 & 2 & 0 & 32.764 & -0.06 & 0.00 & 0.00 & 0.00 & 0.00 & 0.00 \\
\hline 1 & 0 & -2 & -2 & 0 & -9.530 & -0.06 & 0.00 & 0.00 & 0.00 & 0.00 & 0.00 \\
\hline 1 & 0 & 2 & -2 & 0 & 23.775 & -0.07 & 0.00 & 0.00 & 0.00 & 0.00 & 0.00 \\
\hline 1 & 0 & 0 & -4 & 0 & -10.085 & -0.14 & 0.00 & -0.01 & 0.00 & 0.00 & 0.00 \\
\hline 2 & 0 & 0 & -4 & 0 & -15.906 & -0.13 & 0.00 & 0.00 & 0.00 & 0.00 & 0.00 \\
\hline 0 & 0 & 2 & 4 & 2 & 4.793 & -0.07 & 0.00 & 0.03 & 0.00 & 0.00 & 0.00 \\
\hline 0 & 0 & 2 & -1 & 2 & 25.420 & -0.07 & 0.00 & 0.03 & 0.00 & 0.00 & 0.00 \\
\hline-2 & 0 & 2 & 4 & 2 & 7.349 & -0.12 & 0.00 & 0.05 & 0.00 & 0.00 & 0.00 \\
\hline 2 & 0 & 2 & 2 & 2 & 4.684 & -0.11 & 0.00 & 0.05 & 0.00 & 0.00 & 0.00 \\
\hline 0 & -1 & 2 & 0 & 1 & 14.162 & -0.07 & 0.00 & 0.03 & 0.00 & 0.00 & 0.00 \\
\hline 0 & 0 & -2 & 0 & $i$ & -13.579 & -0.06 & 0.00 & 0.03 & 0.00 & 0.00 & 0.00 \\
\hline 0 & 0 & 4 & -2 & 2 & 12.663 & 0.09 & 0.00 & -0.04 & 0.00 & 0.00 & 0.00 \\
\hline
\end{tabular}


TABLE 1 Continued. The ZMOA-1990 nutation series.

\begin{tabular}{|c|c|c|c|c|c|c|c|c|c|c|c|}
\hline \multicolumn{5}{|c|}{$\begin{array}{c}\text { Fundamental } \\
\text { arguments }\end{array}$} & \multirow{2}{*}{$\begin{array}{c}\text { Period } \\
\text { (solar days) }\end{array}$} & \multirow{2}{*}{$\begin{array}{l}\Delta \psi_{i n} \\
\text { (mas) }\end{array}$} & \multirow{2}{*}{$\begin{array}{c}\Delta \dot{\psi}_{i n} \\
\text { (mas/cy) }\end{array}$} & \multirow{2}{*}{$\begin{array}{c}\Delta \varepsilon_{i n} \\
\text { (mas) }\end{array}$} & \multirow{2}{*}{$\begin{array}{c}\Delta \dot{\varepsilon}_{\text {in }} \\
\text { (mas/cy) }\end{array}$} & \multirow{2}{*}{$\begin{array}{l}\Delta \psi_{\text {out }} \\
\text { (mas) }\end{array}$} & \multirow{2}{*}{$\begin{array}{l}\Delta \varepsilon_{\text {out }} \\
\text { (mas) }\end{array}$} \\
\hline$l$ & $l$ & $F$ & $D$ & $\Omega$ & & & & & & & \\
\hline 0 & 1 & 0 & 0 & 2 & 409.234 & 0.07 & 0.00 & -0.03 & 0.00 & 0.00 & 0.00 \\
\hline 1 & 1 & 2 & -2 & 2 & 22.469 & 0.13 & 0.00 & -0.05 & 0.00 & 0.00 & 0.00 \\
\hline 3 & 0 & 2 & -2 & 2 & 8.745 & 0.09 & 0.00 & -0.04 & 0.00 & 0.00 & 0.00 \\
\hline-2 & 0 & 2 & 2 & 2 & 14.632 & 0.13 & 0.00 & -0.06 & 0.00 & 0.00 & 0.00 \\
\hline-1 & 0 & 0 & 0 & 2 & -27.333 & 0.14 & 0.00 & -0.06 & 0.00 & 0.00 & 0.00 \\
\hline 0 & 0 & -2 & 2 & 1 & -169.002 & 0.09 & 0.00 & -0.04 & 0.00 & 0.00 & 0.00 \\
\hline 0 & 1 & 2 & 0 & 1 & 13.143 & 0.08 & 0.00 & -0.04 & 0.00 & 0.00 & 0.00 \\
\hline-1 & 0 & 4 & 0 & 2 & 9.057 & 0.11 & 0.00 & -0.05 & 0.00 & 0.00 & 0.00 \\
\hline 2 & 1 & 0 & -2 & 0 & 131.671 & 0.11 & 0.00 & 0.00 & 0.00 & 0.00 & 0.00 \\
\hline 2 & 0 & 0 & 2 & 0 & 7.127 & 0.06 & 0.00 & 0.00 & 0.00 & 0.00 & 0.00 \\
\hline 2 & 0 & 2 & -2 & 1 & 12.787 & 0.10 & 0.00 & -0.05 & 0.00 & 0.00 & 0.00 \\
\hline 2 & 0 & -2 & 0 & 1 & -943.227 & 0.07 & 0.00 & -0.04 & 0.00 & 0.00 & 0.00 \\
\hline 1 & -1 & 0 & -2 & 0 & -29.263 & 0.09 & 0.00 & 0.00 & 0.00 & 0.00 & 0.00 \\
\hline-1 & 0 & 0 & 1 & 1 & -388.267 & 0.10 & 0.00 & -0.04 & 0.00 & 0.00 & 0.00 \\
\hline-1 & -1 & 0 & 2 & 1 & 35.026 & 0.07 & 0.00 & -0.04 & 0.00 & 0.00 & 0.00 \\
\hline 0 & 1 & 0 & 1 & 0 & 27.322 & 0.05 & 0.00 & 0.00 & 0.00 & 0.00 & 0.00 \\
\hline 3 & 0 & 2 & 2 & 2 & 4.003 & -0.01 & 0.00 & 0.01 & 0.00 & 0.00 & 0.00 \\
\hline 1 & 0 & 2 & 4 & 2 & 4.083 & -0.02 & 0.00 & 0.01 & 0.00 & 0.00 & 0.00 \\
\hline 4 & 0 & 2 & 0 & 2 & 4.579 & -0.03 & 0.00 & 0.01 & 0.00 & 0.00 & 0.00 \\
\hline 2 & 0 & 2 & 2 & 1 & 4.680 & -0.02 & 0.00 & 0.01 & 0.00 & 0.00 & 0.00 \\
\hline 0 & 0 & 2 & 4 & 1 & 4.789 & -0.01 & 0.00 & 0.01 & 0.00 & 0.00 & 0.00 \\
\hline 3 & 0 & 2 & 0 & 1 & 5.488 & -0.05 & 0.00 & 0.02 & 0.00 & 0.00 & 0.00 \\
\hline 1 & 1 & 2 & 2 & 2 & 5.557 & 0.01 & 0.00 & -0.01 & 0.00 & 0.00 & 0.00 \\
\hline 1 & -1 & 2 & 2 & 2 & 5.731 & -0.06 & 0.00 & 0.02 & 0.00 & 0.00 & 0.00 \\
\hline-1 & 0 & 2 & 4 & 1 & 5.797 & -0.03 & 0.00 & 0.01 & 0.00 & 0.00 & 0.00 \\
\hline-1 & -1 & 2 & 4 & 2 & 5.895 & -0.02 & 0.00 & 0.01 & 0.00 & 0.00 & 0.00 \\
\hline $\begin{array}{r}-1 \\
2\end{array}$ & $\begin{array}{r}-1 \\
1\end{array}$ & 2 & 0 & 2 & 6.733 & 0.04 & 0.00 & -0.02 & 0.00 & 0.00 & 0.00 \\
\hline 0 & 0 & 4 & 0 & 2 & 6.817 & 0.02 & 0.00 & -0.01 & 0.00 & 0.00 & 0.00 \\
\hline 2 & 0 & 2 & 0 & 0 & 6.846 & 0.03 & 0.00 & 0.00 & 0.00 & 0.00 & 0.00 \\
\hline 0 & 1 & 2 & 2 & 2 & 6.961 & 0.05 & 0.00 & -0.02 & 0.00 & 0.00 & 0.00 \\
\hline 1 & 0 & 2 & $i$ & 2 & 6.976 & 0.03 & 0.00 & -0.01 & 0.00 & 0.00 & 0.00 \\
\hline 2 & -1 & 2 & 0 & 2 & 6.991 & -0.05 & 0.00 & 0.02 & 0.00 & 0.00 & 0.00 \\
\hline 0 & 0 & 2 & 2 & 0 & 7.081 & 0.04 & 0.00 & 0.00 & 0.00 & 0.00 & 0.00 \\
\hline 2 & 0 & 0 & 2 & 1 & 7.135 & -0.01 & 0.00 & 0.01 & 0.00 & 0.00 & 0.00 \\
\hline 0 & -1 & 2 & 2 & 1 & 7229 & -0.04 & 0.00 & 0.02 & 0.00 & 0.00 & 0.00 \\
\hline-2 & 0 & 2 & 4 & $i$ & 7341 & -0.02 & 0.00 & 0.01 & 0.00 & 0.00 & 0.00 \\
\hline 0 & -1 & 2 & 2 & 2 & 7.236 & -0.01 & 0.00 & 0.01 & 0.00 & 0.00 & 0.00 \\
\hline 0 & 0 & 0 & 4 & 0 & 7.383 & 0.05 & 0.00 & 0.00 & 0.00 & 0.00 & 0.00 \\
\hline 0 & 0 & 0 & 4 & 1 & 7.391 & -0.02 & 0.00 & 0.01 & 0.00 & 0.00 & 0.00 \\
\hline 1 & 0 & 4 & .2 & 2 & 8.676 & 0.02 & 0.00 & -0.01 & 0.00 & 0.00 & 0.00 \\
\hline 3 & 0 & 2 & -2 & 1 & 8.734 & 0.02 & 0.00 & -0.01 & 0.00 & 0.00 & 0.00 \\
\hline 1 & 1 & 2 & 0 & $i$ & 8.898 & 0.04 & 0.00 & -0.02 & 0.00 & 0.00 & 0.00 \\
\hline-1 & 0 & 4 & 0 & 1 & 9.045 & 0.02 & 0.00 & -0.01 & 0.00 & 0.00 & 0.00 \\
\hline 0 & 1 & 2 & 1 & 2 & 9.107 & -0.02 & 0.00 & 0.01 & 0.00 & 0.00 & 0.00 \\
\hline-3 & 0 & 0 & 0 & 1 & -9.172 & -0.01 & 0.00 & 0.01 & 0.00 & 0.00 & 0.00 \\
\hline-1 & 1 & 2 & 2 & 2 & 9.313 & 0.06 & 0.00 & -0.02 & 0.00 & 0.00 & 0.00 \\
\hline 0 & 0 & 2 & 1 & 1 & 9.327 & 0.03 & 0.00 & -0.01 & 0.00 & 0.00 & 0.00 \\
\hline 1 & -1 & 2 & 0 & 1 & 9.354 & -0.04 & 0.00 & 0.02 & 0.00 & 0.00 & 0.00 \\
\hline-1 & 0 & 0 & -2 & 1 & -9.600 & -0.04 & 0.00 & 0.03 & 0.00 & 0.00 & 0.00 \\
\hline-1 & -1 & 2 & 2 & 1 & 9.799 & -0.05 & 0.00 & 0.02 & 0.00 & 0.00 & 0.00 \\
\hline 1 & -1 & 0 & 2 & 0 & 9.874 & 0.05 & 0.00 & 0.00 & 0.00 & 0.00 & 0.00 \\
\hline$i$ & 0 & 0 & -4 & 1 & -10.070 & -0.01 & 0.00 & 0.01 & 0.00 & 0.00 & 0.00 \\
\hline-1 & 0 & 0 & 4 & 1 & 10.100 & -0.02 & 0.00 & 0.01 & 0.00 & 0.00 & 0.00 \\
\hline-1 & -1 & 0 & 4 & 0 & 10.371 & 0.01 & 0.00 & 0.00 & 0.00 & 0.00 & 0.00 \\
\hline 2 & 1 & 2 & -2 & 2 & 12.377 & 0.03 & 0.00 & -0.01 & 0.00 & 0.00 & 0.00 \\
\hline 0 & 0 & 4 & -2 & 1 & 12.639 & 0.02 & 0.00 & -0.01 & 0.00 & 0.00 & 0.00 \\
\hline
\end{tabular}


TABLE 1 Continued. The ZMOA-1990 nutation series.

\begin{tabular}{|c|c|c|c|c|c|c|c|c|c|c|c|}
\hline \multicolumn{5}{|c|}{$\begin{array}{c}\text { Fundamental } \\
\text { arguments }\end{array}$} & \multirow{2}{*}{$\begin{array}{c}\text { Period } \\
\text { (solar days) }\end{array}$} & \multirow{2}{*}{$\begin{array}{l}\Delta \psi_{\text {in }} \\
\text { (mas) }\end{array}$} & \multirow{2}{*}{$\begin{array}{c}\Delta \psi_{i n} \\
\text { (mas/cy) }\end{array}$} & \multirow{2}{*}{$\begin{array}{c}\Delta \varepsilon_{i n} \\
\text { (mas) }\end{array}$} & \multirow{2}{*}{$\begin{array}{c}\Delta \dot{\varepsilon}_{\text {in }} \\
\text { (mas/cy) }\end{array}$} & \multirow{2}{*}{$\begin{array}{l}\Delta \psi_{\text {out }} \\
\text { (mas) }\end{array}$} & \multirow{2}{*}{$\begin{array}{l}\Delta \varepsilon_{\text {out }} \\
\text { (mas) }\end{array}$} \\
\hline$l$ & $l^{\prime}$ & $\bar{F}$ & $D$ & $\boldsymbol{\Omega}$ & & & & & & & \\
\hline 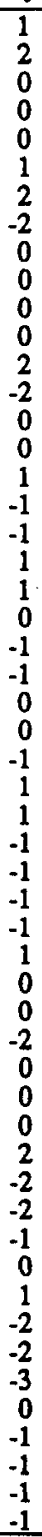 & $\begin{array}{r}0 \\
1 \\
0 \\
0 \\
1 \\
0 \\
-1 \\
0 \\
0 \\
0 \\
1 \\
-1 \\
0 \\
0 \\
-2 \\
0 \\
1 \\
1 \\
-1 \\
1 \\
0 \\
0 \\
-1 \\
1 \\
0 \\
0 \\
-1 \\
-1 \\
-1 \\
0 \\
0 \\
0 \\
0 \\
0 \\
0\end{array}$ & 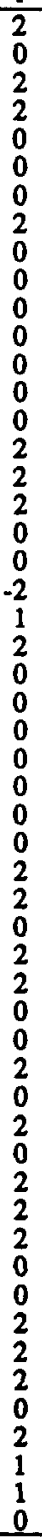 & $\begin{array}{r}-1 \\
0 \\
0 \\
0 \\
2 \\
1 \\
0 \\
2 \\
-2 \\
2 \\
-2 \\
2 \\
-4 \\
4 \\
2 \\
-4 \\
-2 \\
0 \\
0 \\
0 \\
0 \\
0 \\
0 \\
2 \\
-1 \\
1 \\
0 \\
0 \\
-2 \\
2 \\
-2 \\
-2 \\
2 \\
0 \\
-4 \\
-2 \\
0 \\
0 \\
-2 \\
-2 \\
0 \\
-2 \\
-2 \\
0 \\
0 \\
0 \\
-1 \\
-\end{array}$ & $\begin{array}{l}7 \\
2 \\
0 \\
1 \\
3 \\
1 \\
0 \\
0 \\
0 \\
1 \\
2 \\
2\end{array}$ & 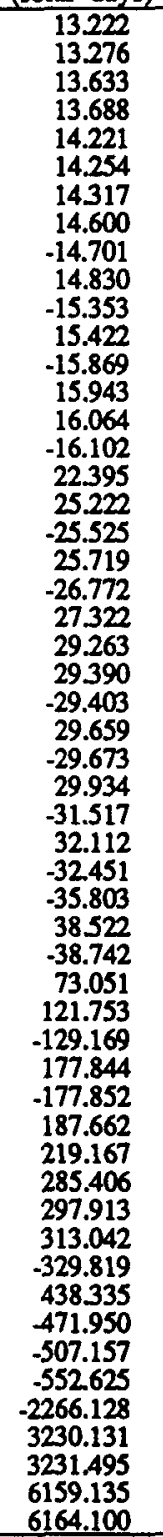 & $\begin{array}{r}-0.03 \\
-0.03 \\
-0.01 \\
0.02 \\
0.02 \\
-0.03 \\
0.04 \\
0.02 \\
0.01 \\
-0.05 \\
-0.03 \\
-0.02 \\
-0.01 \\
0.01 \\
0.02 \\
-0.01 \\
0.03 \\
0.04 \\
0.02 \\
-0.03 \\
0.03 \\
-0.02 \\
-0.02 \\
-0.01 \\
0.03 \\
-0.04 \\
-0.02 \\
0.05 \\
0.03 \\
-0.04 \\
0.03 \\
-0.01 \\
0.03 \\
-0.04 \\
-0.05 \\
0.03 \\
-0.02 \\
-0.09 \\
-0.01 \\
0.13 \\
-0.03 \\
-0.01 \\
-0.01 \\
-0.04 \\
0.04 \\
0.03 \\
0.02 \\
0.03 \\
0.02 \\
-0.02 \\
0.13 \\
-0.15 \\
0.03 \\
0.07 \\
\end{array}$ & 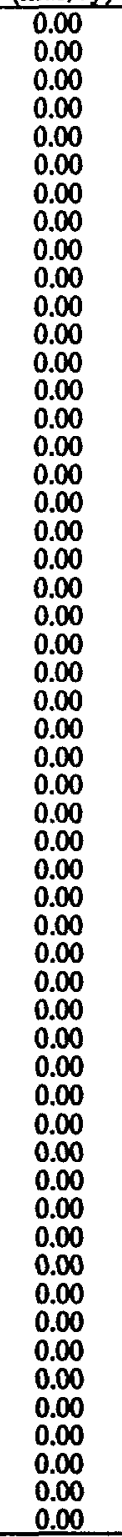 & $\begin{array}{r}0.01 \\
0.00 \\
0.00 \\
0.00 \\
-0.01 \\
0.00 \\
0.00 \\
-0.01 \\
-0.01 \\
0.02 \\
0.02 \\
0.01 \\
0.01 \\
-0.01 \\
0.00 \\
0.01 \\
-0.01 \\
-0.02 \\
-0.01 \\
0.02 \\
-0.01 \\
0.00 \\
0.01 \\
0.01 \\
-0.02 \\
0.02 \\
0.02 \\
-0.03 \\
-0.01 \\
0.02 \\
-0.01 \\
0.01 \\
0.00 \\
0.02 \\
0.02 \\
0.00 \\
0.01 \\
0.07 \\
0.01 \\
-0.02 \\
0.01 \\
0.00 \\
0.00 \\
0.01 \\
-0.01 \\
-0.01 \\
-0.01 \\
0.00 \\
-0.01 \\
0.00 \\
-0.05 \\
0.03 \\
-0.01 \\
-0.04 \\
\end{array}$ & $\begin{array}{l}0.00 \\
0.00 \\
0.00 \\
0.00 \\
0.00 \\
0.00 \\
0.00 \\
0.00 \\
0.00 \\
0.00 \\
0.00 \\
0.00 \\
0.00 \\
0.00 \\
0.00 \\
0.00 \\
0.00 \\
0.00 \\
0.00 \\
0.00 \\
0.00 \\
0.00 \\
0.00 \\
0.00 \\
0.00 \\
0.00 \\
0.00 \\
0.00 \\
0.00 \\
0.00 \\
0.00 \\
0.00 \\
0.00 \\
0.00 \\
0.00 \\
0.00 \\
0.00 \\
0.00 \\
0.00 \\
0.00 \\
0.00 \\
0.00 \\
0.00 \\
0.00 \\
0.00 \\
0.00 \\
0.00 \\
0.00 \\
0.00 \\
0.00 \\
0.00 \\
0.00 \\
0.00 \\
0.00 \\
\end{array}$ & $\begin{array}{l}0.00 \\
0.00 \\
0.00 \\
0.00 \\
0.00 \\
0.00 \\
0.00 \\
0.00 \\
0.00 \\
0.00 \\
0.00 \\
0.00 \\
0.00 \\
0.00 \\
0.00 \\
0.00 \\
0.00 \\
0.00 \\
0.00 \\
0.00 \\
0.00 \\
0.00 \\
0.00 \\
0.00 \\
0.00 \\
0.00 \\
0.00 \\
0.00 \\
0.00 \\
0.00 \\
0.00 \\
0.00 \\
0.00 \\
0.00 \\
0.00 \\
0.00 \\
0.00 \\
0.00 \\
0.00 \\
0.00 \\
0.00 \\
0.00 \\
0.00 \\
0.00 \\
0.00 \\
0.00 \\
0.00 \\
0.00 \\
0.00 \\
0.00 \\
0.00 \\
0.00 \\
0.00 \\
0.00 \\
\end{array}$ & $\begin{array}{l}0.00 \\
0.00 \\
0.00 \\
0.00 \\
0.00 \\
0.00 \\
0.00 \\
0.00 \\
0.00 \\
0.00 \\
0.00 \\
0.00 \\
0.00 \\
0.00 \\
0.00 \\
0.00 \\
0.00 \\
0.00 \\
0.00 \\
0.00 \\
0.00 \\
0.00 \\
0.00 \\
0.00 \\
0.00 \\
0.00 \\
0.00 \\
0.00 \\
0.00 \\
0.00 \\
0.00 \\
0.00 \\
0.00 \\
0.00 \\
0.00 \\
0.00 \\
0.00 \\
0.00 \\
0.00 \\
0.00 \\
0.00 \\
0.00 \\
0.00 \\
0.00 \\
0.00 \\
0.00 \\
0.00 \\
0.00 \\
0.00 \\
0.00 \\
0.00 \\
0.00 \\
0.00 \\
0.00 \\
\end{array}$ \\
\hline
\end{tabular}

The nutation series is evaluated using sin $\theta j$ for the in-phase component of the nutation in longitude, $\Delta \psi$, and $\cos \theta j$ for the out-of-phase component. For the nutetion in obliquity, $\Delta \varepsilon, \cos \theta j$ is used for the in-phase component and in $\theta j$ for the out-of-phase component, where $\theta j$ is the argument of the nutwion (sce Herring at al. [1990] for details). The coefficients are referenced to J2000, and the rates are applied from this epoch. 
Since the ZMOA-1990 series is largely a geophysical one, it does not match the VLBI derived coefficients exactly. In particular, there are four notable differences which are discussed in Herring et al. [1990]. In decreasing order of significance they are: (1) the out-of-phase correction to the retrograde annual nutation (0.39 \pm 0.04 mas); (2) the in-phase correction to the prograde 13.7 day nutation $(-0.25 \pm 0.04$ mas); (3) the amplitude of a nutation at the resonance frequency of the retrograde free core nutation (RFCN) mode $(0.26 \pm 0.04 \mathrm{mas})$; and (4) the out-of-phase correction to the prograde annual nutation $(0.13 \pm 0.04)$. Our aim here is to discuss the likely causes of these differences and the impact of these causes on the ZMOA-1990 nutation series. Items (3) and (4) are discussed in detail in Herring et al. [1990] and will not be discussed further here except to mention that item (3) indicates the detection of a signal, amplitude 0.26 mas, at the resonance frequency of the RFCN mode, and item (4) is disturbing in that there is no apparent explanation for its presence. We are now investigating the possibility that this latter term arises from the annual term associated with the same general relativistic effect which causes de Sitter geodetic precession.

An additional complication which has arisen in developing models for the motion of the Earth in inertial space is that the conventional nutations no longer appear to be the only "forced" motions of the Earth. Recent computations of the effects of tidally induced ocean currents on UT1 by Brosche et al. [1989] have shown that there should be diurnal and semidiurnal variations in the rotation rate of the Earth with amplitudes of order 0.3 mas ( 0.02 milli-time-seconds, $\mathrm{ms}$ ). These signals have now been observed with VLBI [Dong and Herring, 1990], and are likely to be responsible for the second difference noted above. To further complicate matters, it also seems likely that the currently available solid-earth tide and ocean-tidal loading models are not adequate for modeling high precision geodetic data. Therefore not only must a new nutation series be obtained, but also models for prograde diurnal polar motion, prograde and retrograde semidiurnal polar motion, diumal and semidiumal UT1 variations, and tidal displacements in the diurnal and semidiurnal bands need to be adopted. Since these new tidal models are likely to arise from ocean effects, and thus contain multiple spherical harmonic coefficients for a given temporal frequency, a method needs to be adopted for separating deformations from rotational variations.

\section{Discussion of differences between ZMOA-1990 and VLBI results}

As discussed in Herring et al. [1990], the most likely cause for the difference at the retrograde annual frequency is a dissipative process acting at or very near the core-mantle boundary. It is unlikely that this process can be accommodated with the current anelasticity models for the mantle because these models affect the eigenfunction of RFCN mode more than the resonance frequency, and thus impact many terms in the nutation series and not just the retrograde annual nutation. Also, the anelasticity models affect the inphase nutation amplitude more than the out-of-phase component and thus would change terms which currently show no disagreement between theory and observation. It is also unlikely that this difference arises from the ocean tide effects on UT1 discussed in the introduction because of the small size of the $\psi_{1}$ tide that drives this nutation.

The likely effects of dissipation on the core-mantle boundary have been studied by estimating selected coefficients of the normalized response function, $\eta(\sigma)$, directly from the nutation angle data. The functional form for $\eta(\sigma)$ used by Mathews et al is:

$$
\eta(\sigma)=R+R^{\prime}(1+\sigma)+\Sigma_{\alpha} R \alpha\left(\sigma-\sigma_{\alpha}\right)
$$

where $\alpha$ sums over the four normal modes; CW, Chandler wobble; RFCN, retrograde free core nutation; PFCN, prograde free core nutation; and ICW, inner core wobble; $\sigma_{\alpha}$ and $R_{\alpha}$ denote the eigenfrequencies and "oscillator strengths", respectively; and $\sigma$ is the frequency of the forced nutations seen from the rotating Earth. (See Mathews et al., 1990a for detailed discussions of this form of expansion.) The frequencies are in cycles per sidereal day (cpsd). For studying core-mantle boundary dissipation the $R_{\alpha}$ and $\sigma_{\alpha}$ for the RFCN mode were estimated as complex values. The estimates of these four parameters are given in Table 2 for the entry ZMOA-1990-2 along with the values computed from the geophysical theory (simply ZMOA-1990) and the values obtained when the real part of $R^{\prime}$ is also estimated (ZMOA-1990-1). (For historical reasons this later solution which will be discussed below is entitled ZMOA-1990-1.) As expected, the estimation of these parameters reduced the difference between the observed value for the out-of-phase component of the retrograde annual nutation from -0.39 mas to 0.01 mas without affecting greatly the other terms in the nutation series. The most affected nutation amplitudes were the out-of-phase terms for the retrograde 18.6 
year and prograde semiannual nutations. The nutation series terms which differ between ZMOA-1990 and ZMOA-1990-2 by more 0.01 mas are given in Table 3.

TABLE 2. Standard and Estimated values for selected terms in the Normalized Response Function Model (see text for discussion).

\begin{tabular}{|c|c|c|c|c|c|}
\hline \multirow[t]{2}{*}{ Series } & \multicolumn{2}{|c|}{$R_{R F C N}$} & \multicolumn{2}{|c|}{$\sigma_{R F C N}$} & \multirow{2}{*}{$\begin{array}{c}R^{\prime} \\
\text { Real }\end{array}$} \\
\hline & Real & Imag. & Real (cpsd) & Imag (cpsd) & \\
\hline ZMOA-1990 & $-1.1978 \times 10^{-4}$ & - & -1.0023203 & - & -0.28034 \\
\hline ZMOA-1990-1 & $\begin{array}{c}-1.1978 \times 10^{-4} \pm \\
0.0012 \times 10^{-4}\end{array}$ & $\begin{array}{l}0.0075 \times 10^{-4} \pm \\
0.0012 \times 10^{-4}\end{array}$ & $\begin{array}{c}-1.0023207 \pm \\
0.0000020\end{array}$ & $\begin{array}{l}0.0000168 \pm \\
0.0000020\end{array}$ & $\begin{array}{c}-0.2487 \pm \\
0.0050\end{array}$ \\
\hline ZMOA-1990-2 & $\begin{array}{c}-1.1976 \times 10^{-4} \pm \\
0.0012 \times 10^{-4}\end{array}$ & $\begin{array}{l}0.0075 \times 10^{-4} \pm \\
0.0012 \times 10^{-4}\end{array}$ & $\begin{array}{c}-1.0023206 \pm \\
0.0000020\end{array}$ & $\begin{array}{l}0.0000168 \pm \\
0.0000020\end{array}$ & -0.28034 \\
\hline
\end{tabular}

TABLE 3. Coefficients of the ZMOA-1990-2 nutation series that differ from ZMOA-1990.

\begin{tabular}{|c|c|c|c|c|c|c|c|c|c|c|c|}
\hline \multicolumn{5}{|c|}{$\begin{array}{l}\text { Fundamental } \\
\text { arguments }\end{array}$} & \multirow{2}{*}{$\begin{array}{c}\text { Period } \\
\text { (solar days) }\end{array}$} & \multirow{2}{*}{$\begin{array}{c}\Delta \psi_{\text {in }} \\
\text { (mas) }\end{array}$} & \multirow{2}{*}{$\begin{array}{c}\Delta \dot{\psi}_{i n} \\
(\mathrm{mas} / \mathrm{cy})\end{array}$} & \multirow{2}{*}{$\begin{array}{c}\Delta \varepsilon_{i n} \\
\text { (mas) }\end{array}$} & \multirow{2}{*}{$\begin{array}{c}\Delta \dot{\varepsilon}_{\text {in }} \\
\text { (mas/cy) }\end{array}$} & \multirow{2}{*}{$\begin{array}{l}\Delta \psi_{\text {out }} \\
\text { (mas) }\end{array}$} & \multirow{2}{*}{$\begin{array}{l}\Delta \varepsilon_{\text {out }} \\
\text { (mas) }\end{array}$} \\
\hline$l$ & $l$ & $F$ & $D$ & $\Omega$ & & & & & & & \\
\hline 0 & 0 & 0 & 0 & 1 & -6798.383 & -17206.70 & -17.43 & 9205.25 & 0.90 & 3.75 & 1.68 \\
\hline 0 & 0 & 2 & -2 & 2 & 182.621 & -1317.14 & -0.16 & 573.05 & -0.31 & -1.50 & -0.52 \\
\hline 0 & 0 & 2 & 0 & 2 & 13.661 & -227.56 & -0.02 & 97.79 & -0.05 & -0.02 & 0.01 \\
\hline 0 & 0 & 0 & 0 & 2 & -3399.192 & 207.51 & 0.02 & -89.77 & 0.05 & -0.08 & -0.03 \\
\hline 0 & 1 & 0 & 0 & 0 & 365.260 & 147.64 & -0.36 & 732 & -0.02 & 0.82 & -0.28 \\
\hline 1 & 0 & 0 & 0 & 0 & 27.555 & 71.11 & 0.01 & -0.67 & 0.00 & -0.03 & 0.03 \\
\hline 0 & 1 & 2 & -2 & 2 & 121.749 & -51.68 & 0.12 & 22.44 & -0.07 & -0.06 & -0.02 \\
\hline 0 & 0 & 2 & 0 & 1 & 13.633 & -38.71 & -0.04 & 20.06 & 0.00 & -0.01 & 0.00 \\
\hline 1 & 0 & 2 & 0 & 2 & 9.133 & -30.12 & 0.00 & 12.89 & -0.01 & 0.03 & 0.01 \\
\hline
\end{tabular}

From the form of the normalized response function it is clear the difference between the in-phase part of the prograde 13.66 day nutation can be reduced by estimating a correction to the $R^{\prime}$ coefficient. The results of such an estimation are also given in Table 2 for the entry ZMOA-1990-1. (There was no significant difference to the out-of-phase term for this nutation amplitude and therefore the imaginary part of $R^{\prime}$ was not estimated.) The nutation series coefficients which differ from ZMOA-1990 are given in Table 4. However, as mentioned in the introduction, recent investigations have shown that the difference in the 13.66 day nutation is likely to arise from aliasing of the diumal UT1 variations into the estimates of the nutations. Trial solutions, using about 250 of the approximately 1000 available VLBI experiments, have shown that estimating diurnal UT1 variations reduces the difference between the ZMOA-1990 value for the 13.66 day nutation amplitude and the estimated value to less than 0.05 mas: a difference consistent with uncertainty of the estimated value. For this reason, the ZMOA-1990-1 nutation series, while matching the existing VLBI nutation angles better than any other series, is not likely to be correct. The estimated values of the diurnal UT1 variations match those predicted by Brosche et al. [1989] to within about 10\%; in the semidiurnal band, the VLBI estimates are about half the size of the Brosche et al. predictions.

For the solutions in which the coefficients of the normalized response function were estimated, the precession constant and linear rate of change of the obliquity of the ecliptic were more precisely estimated because the amplitudes of the $\mathbf{1 8 . 6}$ year nutations were effectively constrained by the normalized response function and rigid Earth nutation series. In Table 5, we give the estimates of the corrections to the luni-solar precession constant, $\Delta p$, and $\Delta d \theta d d$ for each of the ZMOA nutation series and for the solution given in Herring et al. [1990]. We also give the difference between the estimates of the out-of-phase component of the 18.6 year period nutation in longitude for each of these series and the ZMOA-1990 value. This particular nutation series coefficient is the one most highly correlated (-77\%) with the correction to the precession constant. For both ZMOA-1990-1 and ZMOA-1990-2 the value of $\Delta d$ ded is very close to zero as should be expected [see e.g., Rochester, 1976]. 
TABLE 4. Coefficients of the ZMOA-1990-1 nutation series that differ from ZMOA-1990.

\begin{tabular}{|c|c|c|c|c|c|c|c|c|c|c|c|}
\hline \multicolumn{5}{|c|}{$\begin{array}{l}\text { Fundamental } \\
\text { arguments }\end{array}$} & \multirow{2}{*}{$\begin{array}{c}\text { Period } \\
\text { (solar days) }\end{array}$} & \multirow{2}{*}{$\begin{array}{l}\Delta \psi_{i n} \\
\text { (mas) }\end{array}$} & \multirow{2}{*}{$\begin{array}{c}\Delta \psi_{i n} \\
\text { (mas/cy) }\end{array}$} & \multirow{2}{*}{$\begin{array}{c}\Delta \varepsilon_{i n} \\
\text { (mas) }\end{array}$} & \multirow{2}{*}{$\begin{array}{c}\Delta \dot{\varepsilon}_{i n} \\
\text { (mas/cy) }\end{array}$} & \multirow{2}{*}{$\begin{array}{l}\Delta \psi_{\text {owt }} \\
\text { (mas) }\end{array}$} & \multirow{2}{*}{$\begin{array}{l}\Delta \varepsilon_{\text {out }} \\
\text { (mas) }\end{array}$} \\
\hline$l$ & $l$ & $F$ & $D$ & $\Omega$ & & & & & & & \\
\hline 0 & 0 & 0 & 0 & 1 & -6798.383 & -17206.53 & -17.43 & 9205.18 & 0.90 & 3.71 & 1.66 \\
\hline 0 & 0 & 2 & -2 & 2 & 182.621 & -1317.38 & -0.16 & 573.14 & -0.31 & -1.50 & -0.52 \\
\hline 0 & 0 & 2 & 0 & 2 & 13.661 & -228.11 & -0.02 & 98.00 & -0.05 & -0.02 & 0.01 \\
\hline 0 & 0 & 0 & 0 & 2 & -3399.192 & 207.51 & 0.02 & -89.77 & 0.05 & -0.08 & -0.03 \\
\hline 0 & 1 & 0 & 0 & 0 & 365.260 & 147.65 & -0.36 & 7.32 & -0.02 & 0.82 & -0.28 \\
\hline 1 & 0 & 0 & 0 & 0 & 27.555 & 71.11 & 0.01 & -0.70 & 0.00 & -0.03 & 0.03 \\
\hline 0 & 1 & 2 & -2 & 2 & 121.749 & -51.70 & 0.12 & 22.44 & -0.07 & -0.06 & -0.02 \\
\hline 0 & 0 & 2 & 0 & 1 & 13.633 & -38.82 & -0.04 & 20.10 & 0.00 & -0.01 & 0.00 \\
\hline 1 & 0 & 2 & 0 & 2 & 9.133 & -30.23 & 0.00 & 12.93 & -0.01 & 0.03 & 0.01 \\
\hline 0 & -1 & 2 & -2 & 2 & 365.225 & 21.61 & -0.05 & -9.60 & 0.03 & 0.01 & 0.01 \\
\hline 1 & 0 & 0 & -2 & 0 & -31.812 & -15.70 & 0.00 & -0.13 & 0.00 & -0.01 & -0.01 \\
\hline 0 & 0 & 2 & -2 & 1 & 177.844 & 12.92 & 0.01 & -6.98 & 0.00 & 0.02 & 0.00 \\
\hline-1 & 0 & 2 & 0 & 2 & 27.093 & 12.36 & 0.00 & -5.34 & 0.00 & 0.01 & 0.00 \\
\hline$i$ & 0 & 0 & 0 & 1 & 27.667 & 6.33 & 0.01 & -3.33 & 0.00 & 0.00 & 0.00 \\
\hline 0 & 0 & 0 & 2 & 0 & 14.765 & 6.36 & 0.00 & -0.12 & 0.00 & 0.00 & 0.00 \\
\hline-1 & 0 & 2 & 2 & 2 & 9.557 & -5.98 & 0.00 & 2.56 & 0.00 & 0.00 & 0.00 \\
\hline-1 & 0 & 0 & 0 & 1 & -27.443 & -5.80 & -0.01 & 3.15 & 0.00 & 0.00 & 0.00 \\
\hline 1 & 0 & 2 & 0 & 1 & 9.121 & -5.17 & 0.00 & 2.65 & 0.00 & 0.00 & 0.00 \\
\hline 2 & 0 & 0 & -2 & 0 & 205.892 & 4.79 & 0.00 & 0.05 & 0.00 & 0.00 & 0.00 \\
\hline-2 & 0 & 2 & 0 & 1 & 1305.479 & 4.60 & 0.00 & -2.43 & 0.00 & 0.00 & 0.00 \\
\hline 0 & 0 & 2 & 2 & 2 & 7.096 & -3.86 & 0.00 & 1.65 & 0.00 & 0.00 & 0.00 \\
\hline 2 & 0 & 2 & 0 & 2 & 6.859 & -3.11 & 0.00 & 1.32 & 0.00 & 0.00 & 0.00 \\
\hline
\end{tabular}

TABLE 5. Estimated corrections to the LAU-1980 luni-solar precession constant, $\Delta p$; to the rate of change of the obliquity of the ecliptic, $d \mathcal{E} d t$; and to the ZMOA-1990 value for the out-of-phase component of the 18.6 year period nutation in longitude; for the ZMOA-1990 nutation series and its two variants discussed in the text.

\begin{tabular}{cccc}
\hline Series & $\Delta p$ ("/cent) & $\Delta d \varepsilon / d t$ ("/cent) & $\left(\delta \Delta \psi_{i}\right)_{18.6 \text { year }}$ (mas) \\
\hline VLBI: coefficients estimated & $-0.32 \pm 0.13$ & $-0.04 \pm 0.05$ & $2.3 \pm 3.8$ \\
ZMOA-1990 & $-0.27 \pm 0.02$ & $-0.03 \pm 0.006$ & - \\
ZMOA-1990-1 & $-0.30 \pm 0.04$ & $0.015 \pm 0.01^{4}$ & 1.8 \\
ZMOA-1990-2 & $-0.31 \pm 0.04$ & $0.016 \pm 0.01^{5}$ & 1.9 \\
\hline
\end{tabular}

The "VLBI: coefficient estimated" line refers to the solution given in Herring el al. [1990] obtuined when complex coenponenus of 18 nutation amplindes in the series are estimated; the ZMOA-1990 line gives the extimates when only $4 p$ and $\Delta d \varepsilon / d r$ are estimated (in this case the series value for $\left(\Delta \psi_{i}\right)_{18.6}$ yeer is used and no estimate is given for the difference); and the ZMOA-1990-1 and ZMOA-1990-2 lines are for the series obtuined when selected terms in the normalized response function are extimatod. The lattar two cases the values for $\left(\delta \psi_{i}\right)_{18.6}$ year are the differences between each of the series and ZMOA-1990.

\section{Conclusions}

Of the three nutation series presented here, ZMOA-1990-2 is likely to be the most accurate one, although this series should be used in conjunction with diurnal and semi-diumal UT1 variations if the full motion of the Earth in inertial space is to be obtained. Associated with this series is a correction of $-0.31 \pm 0.04$ "/cent to the luni-solar precession constant. This correction is consistent with the value obtained from LLR, $-0.27 \pm$ 0.04 "/cent. To understand the likely errors incurred in using the IAU-1980 nutation series and, to some extent, the uncertainty in ZMOA-1990-2 series, we show in Figure 1 the difference between the ZMOA1990 and IAU-1980 series, and the difference between ZMOA-1990 and ZMOA-1990-1 over the twenty year interval between 1980 and 2000. (The ZMOA-1990-2 yields results almost identical to ZMOA-1990-1 except that the high frequency component arising from the 13.66 day nutation is not present. We do not show this difference for clarity.) Over this twenty year interval, the IAU-1980 nutation series and the IAU-1976 
precession constant are likely to introduce errors in the the realization of an inertial frame of about 70 mas (approximately 28 mas in the celestial pole position). The differences between the ZMOA models is about $10 \%$ of this value, and thus while there is still uncertainty in the appropriate values of the parameters in the geophysical model of the nutations, these uncertainties are probably less that $10 \%$ of the errors in the current IAU nutation series.

FIGURE 1. Differences between ZMOA-1990 and the IAU-1980 nutation in longitude (top figure) and nutation in obliquity (lower figure). Also shown is the difference between ZMOA-1990-1 and ZMOA-1990. These latter values are indicative of the uncertainty in the parameters of the current geophysical models for nutations. The scales have been selected such that each figure represents the same amount of pole displacement.

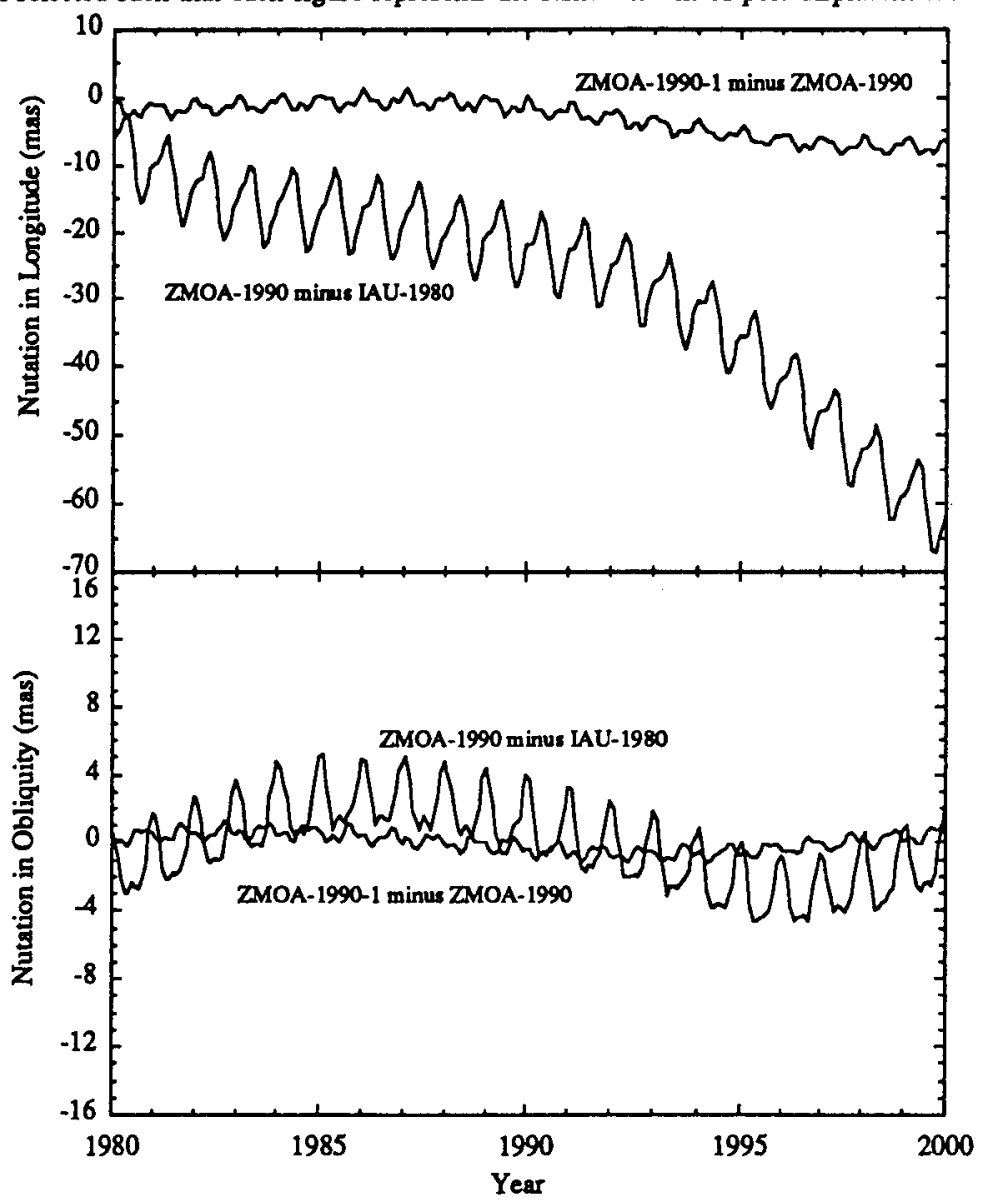

\section{References}

Brosche, P., U. Seiler, J. Sundermann, and J. Wünsch (1989) Astron. Astrophys., 220, 318-320.

Dong. D., and T. A. Herring (1990) EOS Trans. AGU, 71, 482.

Gwinn, C. R., T. A. Herring, and I. I. Shapiro (1986) J. Geophys. Res., 91, 4755-4765.

Hager, B. H., R. W. Clayton, M. A. Richards, R. P. Comer, and A. M. Dziewronski (1985) Nature, 91, 541-545.

Herring, T. A., C. R. Gwinn, and I. I. Shapiro (1986) J. Geophys. Res, 91, 4755-4765, (Correction, 1986, J. Geophys. Res., 91, 14165.) 
Herring, T. A., B. A. Buffett, P. M. Mathews, and I. I. Shapiro (1990) "Forced nutations of the Earth: Influence of inner core dynamics. III. Very long baseline interferometry data analysis," J. Geophys. Res., in press.

Kinoshita, H., and J. Souchay (1990) "The theory of the nutation for the rigid Earth model at the second order," submitted Celes. Mech.

Mathews, P. M., B. A. Buffeth T. A. Herring, and I. I. Shapiro (1990a) "Forced nutations of the Earth: Influence of inner core dynamics. I. Theory," J. Geophys. Res., in press.

Mathews, P. M., B. A. Buffett, T. A. Herring, and I. L. Shapiro (1990b) "Forced nutations of the Earth: Influence of inner core dynamics. II. Numerical results," J. Geophys. Res., in press.

Morelli, A., and A. M. Driewonski (1987) Nature, 325, 867-683.

Neuberg, J., J. Hinderer, and W. Zurn (1987) Geophys. J. R. Astron. Soc, 91, 853-868.

Rochester, M. G. (1976) Geophys. J. R. Astron. Soc., 46, 109-126.

Sailor, R. V., and A. M. Driewonski (1978) Geophys. J. R. Astron. Soc., 53, 559-581.

Seidelmann, P. K. (1982) Celes. Mech., 27, 79-106.

Sipkin, S. A., and T. H. Jordan (1980) Bull. Seism. Soc. Am., 70, 1071-1102.

Wahr, J. M., and Z. Bergen (1986) Geophys. J. R. Astron. Soc., 87, 633-668.

Wahr, J. M., and T. Sasao (1981) Geophys. J. R. Astron. Soc., 64, 747-765.

Williams, G. G., X X Newhall, and J. O. Dickey (1990) "Luni-solar precession-determination from lunar laser ranging." Astron. Astrophys., in press.

Zhu, S.Y., and E. Groten (1989) Astron. J., 98, 1104-1111.

Zhu, S. Y., E. Groten, and Ch. Reigber (1990) Astron. J., 99, 1024-1044.

Acknowledgments. This work was eupported by the National Science Foundetion under grant EAR-89-05560, by the National Aeroneutics and Space Adminiatration under grant NAG 5-538, and by the National Oceanographic and Atmoopheric Administration under grant NA90AA-D-AC481. 